\title{
Governança pública nas cidades inteligentes: revisão teórica sobre seus principais elementos
}

\author{
Luiz Antônio Felix Júnior ${ }^{1,2}$ \\ Luciana Gondim de Almeida Guimarães ${ }^{2}$ \\ Wênyka Preston Leite Batista da Costa ${ }^{3}$ \\ Vera Lúcia $\mathrm{Cruz}^{4}$ \\ Walid Abbas El-Aouar2 ${ }^{2}$ \\ ${ }^{1}$ Instituto Federal de Alagoas, Maceió - AL, Brasil \\ ${ }^{2}$ Universidade Potiguar, Natal - RN, Brasil \\ ${ }^{3}$ Universidade do Estado do Rio Grande do Norte, Mossoró - RN, Brasil \\ ${ }^{4}$ Universidade Federal da Paraíba, João Pessoa - PB, Brasil
}

Uma cidade pode ser definida como inteligente se adotar um estilo inovador de governança colaborativa para projetar políticas urbanas, visando à melhoria da qualidade de vida dos cidadãos. Portanto, este estudo objetivou compreender elementos que colaboram para o desenvolvimento de uma governança pública na perspectiva das cidades inteligentes. A proposta é baseada em uma revisão sistemática da literatura no período de 2009 a 2020. Nessa revisão foi utilizado o Software VOSviewer ${ }^{\circledR}$ como auxiliar. Foram analisadas 32 produções, sendo apresentados: conceitos; tendências e elementos; agenda de pesquisas futuras; quantitativos de pesquisadores, instituições, países e trabalhos mais citados. Conclui-se que o conceito de governança inteligente se dá pela associação entre o uso da tecnologia e o envolvimento dos atores locais, em especial o cidadão, para definição mais acertada das políticas públicas, coprodução de serviços e práticas de governo, gerando uma maior confiança na administração pública. Foram constatados alguns elementos que colaboram para o desenvolvimento da governança inteligente, como: dados; transparência; participação; contexto; cidadão; colaboração; desenvolvimento; tecnologia da informação e comunicação; e meio ambiente. O estudo contribui academicamente por apresentar direcionamentos sobre o tema da governança, temática ainda pouco explorada nas cidades inteligentes. Gerencialmente, pelo levantamento de características existentes na governança da cidade inteligente, servindo de base para o desenvolvimento de projetos de governança nas cidades. Como agenda futura, sugerem-se estudos que abordem a aproximação entre os atores sociais; mecanismos de participação em plataformas eletrônicas; desenvolvimento de modelo de referência com capacidade de inferência estatística.

Palavras-chave: cidades inteligentes, governança inteligente, cidadão 


\section{Gobernanza pública en ciudades inteligentes: revisión teórica sobre sus principales elementos}

Una ciudad puede definirse como inteligente si adopta un estilo innovador de gobernanza colaborativa para diseñar políticas urbanas, con el objetivo de mejorar la calidad de vida de los ciudadanos. Por tanto, este estudio tuvo como objetivo comprender los elementos que colaboran para el desarrollo de la gobernanza pública desde la perspectiva de las ciudades inteligentes. La propuesta se basa en una revisión sistemática de la literatura de 2009 a 2020. En esta revisión se utilizó el software VOSviewer® como auxiliar. Se analizaron 32 producciones, presentándose: conceptos; tendencias y elementos; agenda de investigación futura; número de investigadores, instituciones, países y trabajos más citados. Se concluye que el concepto de gobernanza inteligente se debe a la asociación entre el uso de la tecnología y el involucramiento de los actores locales, especialmente el ciudadano, para una mejor definición de políticas públicas, coproducción de servicios y prácticas gubernamentales, generando mayor confianza. en la administración pública. Se encontraron algunos elementos que contribuyen al desarrollo de la gobernanza inteligente, tales como: datos; transparencia; participación; contexto; ciudadano; colaboración; desarrollo; tecnología de la información y la comunicación; y el medio ambiente. El estudio contribuye académicamente al presentar pautas sobre el tema de la gobernanza, un tema que aún se explora poco en las ciudades inteligentes. Gerencialmente, mediante el relevamiento de las características existentes en la gobernanza de la ciudad inteligente, sirviendo de base para el desarrollo de proyectos de gobernanza en las ciudades. Como agenda futura, se sugieren estudios que aborden la aproximación entre actores sociales; mecanismos de participación en plataformas electrónicas; desarrollo de un modelo de referencia con capacidad de inferencia estadística.

Palabras clave: ciudades inteligentes, gobernanza inteligente, ciudadano

\section{Public governance in smart cities: theoretical review on its main elements}

A city can be defined as intelligent if it adopts an innovative style of collaborative governance to design urban policies, aiming at improving the quality of life of citizens. Therefore, this study aimed to understand elements that collaborate for the development of public governance from the perspective of smart cities. The proposal is based on a systematic review of the literature from 2009 to 2020 . In this review, the VOSviewer ${ }^{\circledR}$ Software was used as an auxiliary. 32 productions were analyzed, being presented: concepts; trends and elements; future research agenda; numbers of researchers, institutions, countries and most cited works. It is concluded that the concept of intelligent governance is due to the association between the use of technology and the involvement of local actors, especially the citizen, for a better definition of public policies, co-production of services and government practices, generating greater confidence in public administration. Some elements that contribute to the development of intelligent governance were found, such as: data; transparency; participation; context; citizen; collaboration; development; information and communication technology; and the environment. The study contributes academically by presenting guidelines on the theme of governance, a theme that is still little explored in smart cities. Managerially, by surveying existing characteristics in the governance of the smart city, serving as a basis for the development of governance projects in cities. As a future agenda, studies are suggested that address the approximation between social actors; mechanisms for participation in electronic platforms; development of a reference model with statistical inference capacity.

Keywords: smart cities, smart governance, citizen 


\section{Introdução}

Uma cidade inteligente é baseada em um bom desempenho que implica uma perspectiva de futuro na economia, na governança, na mobilidade, no meio ambiente e na vida das pessoas. Esse futuro é baseado em uma combinação inteligente de recursos com o auxílio de cidadãos autoconfiantes, independentes e conscientes (GIFFINGER et al., 2007).

Em 2003, já se relatavam vários projetos de cidades inteligentes, fossem eles de transformação ou de iniciativas, visando à melhoria no atendimento do cidadão e na sua qualidade de vida (ODENDAAL, 2003), pois há um número crescente de alianças urbanas e grupos de discussões que buscam reunir teóricos, profissionais e governos na tentativa de sintetizar um futuro urbano comum (ANTHOPOULOS, 2017).

Portanto, o termo inteligente adotado junto à palavra cidade implica, em particular, na ambição implícita ou explícita de uma cidade em melhorar seus padrões econômicos, sociais e ambientais e, consequentemente, na sua competitividade entre cidades (GIFFINGER; HAINDLWAIR; KRAMAR, 2010). O termo inteligente também se associa a cidades pelo uso das TICs (tecnologias da informação e comunicação), que conectam e fortalecem redes de pessoas, empresas, infraestruturas, recursos, energia e espaços, além de fornecerem ferramentas organizacionais e de governança inteligentes.

Dessa forma, as cidades inteligentes resultam da combinação entre capital humano, capital social e TIC, buscando o desenvolvimento econômico (CAPDEVILA; ZARLENGA, 2015) e a realização de políticas públicas que colaborem para um melhor convívio em sociedade (MEIJER; GIL-GARCIA; BolÍVAR, 2016). A participação da sociedade é um aspecto valioso da governabilidade das cidades. E essa participação, tida como social, é considerada um elemento essencial para o desenho de uma cidade inteligente (FELIX JÚNIOR et al., 2020a).

São diversas as dimensões necessárias para as cidades inteligentes. Porém, algumas são cruciais para o avanço de nossa compreensão sobre o que seria uma cidade inteligente. Três delas são: condições contextuais, modelos de governança e a avaliação do valor público (Walravens; Ballon, 2013; MeiJer; Gil-Garcia; Bolívar, 2016). De forma objetiva, na perspectiva de uma necessidade básica e essencial para a existência de uma cidade inteligente, o elemento principal para a sua existência é a governança inteligente (GILGARCIA, 2012; SCHOLL; SCHOLL, 2014). Isso porque, conforme Nesti (2019), uma cidade 
pode ser definida como inteligente se adotar um estilo inovador de governança colaborativa para projetar políticas urbanas, visando à melhoria da qualidade de vida dos cidadãos e a promoção da sustentabilidade ambiental, econômica e social.

A governança de cidades inteligentes ganhou importância nas discussões apenas na literatura mais recente (GLASMEIER; NEBIOLO, 2016), apesar de este ser um elemento chave para a construção da cidade inteligente, como afirma o Parlamento Europeu, ao retratar a governança inteligente como um fator transversal que pode orquestrar e integrar algumas ou todas as outras características inteligentes das cidades (EUROPEAN PARLAMIENT, 2014).

Dessa forma, considerando a ideia da construção de uma cidade inteligente ou de ações que possam promover a sua realização e a governança como um elemento de base para o desenvolvimento de projetos e ações inteligentes nessas cidades, por meio de uma proposta de revisão sistemática da literatura, esta pesquisa objetivou compreender elementos que colaboram para o desenvolvimento de uma governança pública na perspectiva das cidades inteligentes.

Essa proposta não avalia o melhor modelo nem a melhor forma de abordagem da governança inteligente. Seu propósito está na apresentação dos elementos que a compõem e da sua importância, assim como de suas relações com outros possíveis elementos. Para tanto, após esta introdução, é apresentada a composição metodológica adotada no desenvolvimento da pesquisa, na seção 2; o referencial teórico com os conceitos para compreensão da governança na cidade inteligente, na seção 3; os elementos da governança inteligente identificados em pesquisas anteriores baseados em dados numéricos e textuais, na seção 4; e, por fim, as conclusões são obtidas, na seção 5 .

\section{Metodologia}

Buscando o alcance do objetivo pretendido na investigação, realizou-se uma revisão sistemática da literatura. As estratégias de pesquisa foram divididas em dois momentos: revisão teórica, exposta por meio do referencial teórico; e os aspectos da revisão sistemática, responsáveis por evidenciar a produção científica sobre governança na cidade inteligente. 


\subsection{Composição da revisão teórica}

Para compor a revisão teórica, os trabalhos foram selecionados por meio de palavraschave que representassem cada elemento do referencial teórico, por meio do Google Scholar®, sendo estas: governance; smart governance; smart government; open government e e-government. Essa etapa não teve como objetivo apresentar todos os estudos dos temas mencionados, mas apresentar um panorama sobre a governança em cidades inteligentes. Por esse motivo, os temas mencionados foram expostos nesta pesquisa.

Os trabalhos utilizados datam do período de 2000 a 2020, sendo a pesquisa mais antiga a dos autores Lynn Jr., Heinrich e Hill (2000), e a mais atual, a de Felix Júnior et al. (2020b). Os tipos e quantitativos de trabalhos apresentados nesta etapa do estudo estão dispostos conforme o Quadro 1.

\section{Quadro 1 - Tipos e quantitativos de trabalhos abordados no estudo}

\begin{tabular}{|l|l|c|}
\hline \multicolumn{1}{|c|}{ Tipos de trabalho } & \multicolumn{1}{c|}{ Descrição } & Quantidade \\
\hline Artigos, livro, dissertação ou tese & Pesquisas de natureza teórica ou empírica. & 40 \\
\hline Trabalhos de eventos & Pesquisas apresentadas apenas em eventos. & 6 \\
\hline Papéis de governo & $\begin{array}{l}\text { Orientações expressas pelos governos para adoção de } \\
\text { práticas de governança em cidades inteligentes. }\end{array}$ & 3 \\
\hline
\end{tabular}

Fonte: Elaborado pelos autores (2020).

Os temas propostos para compor o referencial teórico da pesquisa, auxiliando no entendimento da governança em uma perspectiva de cidade inteligente, são definidos no Quadro 2:

\section{Quadro 2 - Seções da revisão teórica da pesquisa}

\begin{tabular}{|l|l|}
\hline \multicolumn{1}{|c|}{ Seção de discussão } & \multicolumn{1}{c|}{ Objetivo da seção } \\
\hline Conceituando cidades inteligentes. (Item 3.1) & $\begin{array}{l}\text { Conceituar a cidade inteligente, para que a sua } \\
\text { composição possa ser compreendida. }\end{array}$ \\
\hline Governança e governança inteligente. (Item 3.2) & $\begin{array}{l}\text { Relatar a diferença entre a governança tradicional e a } \\
\text { governança na perspectiva de uma cidade inteligente. }\end{array}$ \\
\hline $\begin{array}{l}\text { Diferença entre governança inteligente e e } \\
\text { governo inteligente. (Item 3.3) }\end{array}$ & $\begin{array}{l}\text { Evidenciar os elementos que distinguem um governo e } \\
\text { uma governança inteligente. }\end{array}$ \\
\hline $\begin{array}{l}\text { Considerações sobre governo aberto e governo } \\
\text { eletrônico (Item 3.4) }\end{array}$ & $\begin{array}{l}\text { Descrever a essência de um governo aberto e um governo } \\
\text { eletrônico como ferramentas de auxílio à governança } \\
\text { inteligente. }\end{array}$ \\
\hline
\end{tabular}

Fonte: Elaborado pelos autores (2020). 


\subsection{Composição da revisão sistemática da literatura}

Dando continuidade à explanação sobre os elementos que compõem a governança inteligente, esta etapa destacou os aspectos da revisão sistemática por meio da base científica Scopus®, com auxílio do Software VOSviewer®.

Para seu desenvolvimento, foram utilizados os critérios estabelecidos e adotados na pesquisa de Ruhlandt (2018), conforme Quadro 3:

\section{Quadro 3 - Etapas de seleção das pesquisas}

\begin{tabular}{|l|l|}
\hline Etapas & Seleção \\
\hline Selecionar bancos de dados para busca. & Scopus® database (Elsevier) \\
\hline $\begin{array}{l}\text { Escolher palavras-chave que estejam inclusas nos títulos } \\
\text { ou resumos dos artigos. }\end{array}$ & "Smart Governance” \\
\hline $\begin{array}{l}\text { Solicitar os filtros que serão utilizados (ex.: período de } \\
\text { busca, tipo de publicações etc.). }\end{array}$ & $\begin{array}{l}\bullet \text { Trabalhos científicos empíricos e de revisão. } \\
\text { permos pesquisados nos títulos, resumos e } \\
\text { palas-chave. }\end{array}$ \\
\hline $\begin{array}{l}\text { Remover artigos duplicados que estão presentes em mais } \\
\text { de uma base. }\end{array}$ & O estudo trabalhou com uma base. \\
\hline $\begin{array}{l}\text { Solicitar que as palavras-chave definidas ocorram pelo } \\
\text { menos uma vez no corpo inteiro do artigo. }\end{array}$ & Foram selecionados 92 trabalhos. \\
\hline $\begin{array}{l}\text { Refinar possíveis falsos positivos com base no texto } \\
\text { completo, lendo, pelo menos, resumos, introdução e } \\
\text { conclusão. }\end{array}$ & Foram selecionados 34 trabalhos. \\
\hline $\begin{array}{l}\text { Adicionar artigos não incluídos na busca, mas } \\
\text { identificados ao longo das leituras das produções } \\
\text { selecionadas. }\end{array}$ & Sem adições. \\
\hline \begin{tabular}{l} 
Número final de trabalhos selecionados \\
\hline
\end{tabular} & 34 trabalhos. \\
\hline
\end{tabular}

Fonte: Elaborado pelos autores com base em Ruhlandt (2018).

A busca das pesquisas relacionadas à governança inteligente foi desenvolvida no banco de publicações da Scopus® database (Elsevier), como utilizado nas pesquisas de Meijer e Bolívar (2016), Bolívar (2019) e Pereira et al. (2018b), por representar o maior banco de dados de artigos e resumos disponíveis na web científica (MONGEON; PAUL-HUS, 2016, De Guimarães; Dorion; SEVero, 2019).

A palavra-chave escolhida foi: "smart governance", termo adotado no estudo de Meijer e Bolívar (2016) e Pereira et al. (2018b). Aspas (“”) foram utilizadas para garantirem exatidão na pesquisa. Nesta busca, foram admitidos apenas trabalhos científicos empíricos e de revisão. O termo pesquisado deveria estar pelo menos nos títulos, resumos e palavras- 
chave. E o período de busca foi de 2009 a 2020, sendo desenvolvida em maio de 2019 e revisada em julho de 2020.

Os falsos positivos são pesquisas que abordam o termo "Smart Governance", contudo em contextos sem associações às iniciativas de cidades inteligentes e à gestão pública. Portanto, foram 34 trabalhos selecionados e analisados.

Selecionadas as pesquisas a serem analisadas, utilizou-se o Software VOSviewer 1.6.15® com o objetivo de observar elementos numéricos e textuais. Como elementos numéricos, foram observados autores que mais publicam sobre o tema, organizações dos autores, países que mais publicam, artigos mais citados e palavras-chave mais recorrentes. Em relação aos elementos textuais, foram observados os termos mais comuns, suas possíveis relações e sua relevância dentro do texto sobre a temática da governança em cidades inteligentes por meio da criação de um mapa de clusters e da relevância dos termos achados.

Para Eck e Waltman (2010), a técnica de abordagem VOS não possui tendência a posicionar itens importantes no centro do mapa, ficando esses itens e os itens menos importantes distribuídos de forma mais correta em áreas centrais ou periféricas, o que confirma o seu propósito de observação de relações e relevância entre os termos.

Para a criação dos elementos numéricos, utilizou-se a opção “criar um mapa baseado em dados bibliográficos". Já no levantamento dos elementos textuais, foi utilizada a opção "criação de mapa baseado em texto (títulos e resumos)".

Por fim, a pesquisa levantou os conceitos de governança inteligente, tendências das pesquisas, elementos da governança inteligente e a proposição de uma agenda de pesquisa baseada em sugestões de pesquisas futuras identificadas nas pesquisas selecionadas.

\section{Referencial teórico}

Este referencial teórico visa discutir elementos que auxiliem na compreensão da governança nas cidades inteligentes. A explanação inicia com a apresentação do conceito de cidade inteligente para que seja possível compreender o papel da governança nessa nova concepção de território. Na sequência, é exposta a conceituação e a diferença entre a governança tradicional das cidades e a governança pública na perspectiva das cidades inteligentes. Posteriormente, é feita uma breve distinção entre governança inteligente e 
governo inteligente. Por fim, são apresentados os conceitos de governo eletrônico, aberto e digital, elementos que colaboram para o bom andamento da governança inteligente.

\subsection{Conceituando cidades inteligentes}

Muitas cidades ao redor do mundo estão enfrentando imensa pressão devido às aceleradas taxas de crescimento nos níveis da população urbana. A noção de cidades inteligentes foi proposta como uma solução para melhorar a sustentabilidade das cidades por meio de uma gestão urbana eficaz de governança, energia e transporte (HAMMAD et al., 2019).

Desse modo, conforme o conceito de cidade inteligente, este é o caminho para alcançar o desenvolvimento por meio do seu domínio multidisciplinar, que congrega várias frentes de ação e habilidades distintas (LOPES; OLIVEIRA, 2017), sendo esse tipo de cidade um ambiente coletivo com novos espaços socioeconômicos, nos quais cidadãos, empresas e governos dispõem de serviços e recursos com uma maior eficiência (LETAIFA, 2015).

Nam e Pardo (2011) reafirmam esse fato, pois, segundo os autores, na atualidade a titulação de cidade inteligente compreende um conjunto de fatores de sinergia, incluindo as soluções tecnológicas, com fatores sociais, técnicos e ambientais da cidade, como um meio de reinventar cidades para uma nova economia e uma sociedade com benefícios comunitários claros e convincentes (EGER, 2009). Em síntese, a transformação das cidades em locais inclusivos, integrados e habitáveis é uma estratégia-chave inclusa no conceito de cidade inteligente (KUMMITHA; CRUTZEN, 2017).

Nessa perspectiva, essas cidades são consideradas ecossistemas complexos, envoltos de inovação e criatividade, objetivando o desenvolvimento de ambiente sustentável e com melhor qualidade de vida para os cidadãos (CAPDEVILA; ZARLENGA, 2015). Para isso, concentra-se, basicamente, em alcançar dois objetivos principais: um padrão de vida elevado de seus cidadãos e o desenvolvimento sustentável da cidade (CAPUTO; WALLETZKY; ŠTEPÁNEK, 2018).

Por esse motivo, governos e órgãos públicos, em todos os níveis, estão adotando a noção de inteligência para distinguir suas políticas e programas para atingir o 
desenvolvimento sustentável, o crescimento econômico e uma melhor qualidade de vida para seus cidadãos (BALLAS, 2013).

Assim, a qualidade de vida torna-se um elemento-chave no contexto das cidades inteligentes (GIFFINGER et al., 2007; NAM; PARDO, 2011; THUZAR, 2011; DEL EsPOSTE et al., 2019). Albino, Berardi e Dangelico (2015) complementam, afirmando que o projeto de uma cidade inteligente tem impacto na qualidade de vida dos cidadãos, promovendo cidadãos informados, educados e participativos.

A qualidade de vida mencionada passa pelo desenvolvimento de espaços que usam novas tecnologias para uma melhor vida na cidade. Alguns exemplos são as redes inteligentes, que ajudam a fazer melhor uso da energia elétrica; os sistemas de transporte, que objetivam otimizar o uso de estradas; e os aplicativos inteligentes, que fornecem aos turistas informações sobre pontos turísticos (MEIJER; THAENS, 2018).

Dessa maneira, deve haver um equilíbrio de fatores, como práticas ambientais inteligentes, governança inteligente, vida inteligente, mobilidade inteligente, pessoas inteligentes e economia inteligente. Esses elementos-chave trabalham juntos para explorar as novas tecnologias que, de forma conjunta, ajudam a concretizar uma cidade inteligente (TAHIR; MALEK, 2016).

Além dos elementos citados, uma cidade inteligente deve apoiar inovações, comunicação (pessoas, serviços, organizações públicas e privadas de diferentes setores da cidade), engajamento dos cidadãos e desenvolvimento de conhecimento, tudo para criar um ambiente de apoio sinérgico (CAPUTO; WALLETZKY; ŠTEPÁNEK, 2018).

Destarte, pode-se inferir que a conceituação de cidades inteligentes apoia-se nas questões tecnológicas, perpassa a inovação e envolve, além destas, a preocupação com o bem-estar dos cidadãos, representado, por exemplo, por infraestrutura para educação e inovação, parcerias empresas-governos, inovação e qualidade de serviços (BIBRI; KROGSTIE, 2017). Conclui-se que todos os esforços realizados para o desenvolvimento sustentável e o crescimento econômico sólido da cidade visam oferecer melhorias na qualidade de vida para os seus cidadãos (NAM; PARDO, 2011, THUZAR, 2011). 


\subsection{Governança e governança inteligente}

Na tentativa de compreender a necessidade da adoção de uma governança inteligente, busca-se, neste espaço, entender o que há de novo nesse conceito que inclui o termo "inteligente" associando-o ao conceito anterior de governança.

A governança pública, em seu modo restrito, pode ser entendida como o conjunto de leis, regras administrativas, posicionamentos judiciais e regras que restringem, determinam e permitem a atividade do governo. Essa atividade é compreendida como a produção e o repasse de serviços com apoio público (LynN; HeINRICH; HILL, 2000). Nota-se que essa governança existe na perspectiva de cumprimentos de normas que visam ao bom funcionamento dos entes públicos.

Já para Odendaal (2003), o termo governança em cidades remete-se às formas pelas quais o governo local gerencia os seus espaços para alcançar o crescimento contínuo, a distribuição e a administração eficaz de seus negócios.

Em um panorama de cidades com sociedade crescente e surgimento de exigências para mudanças no meio em que as pessoas vivem, manifesta-se a figura da cidade inteligente e, conforme Meijer, Gil-Garcia e Bolívar (2016), os desafios enfrentados pelas cidades inteligentes superam as capacidades do tradicionalismo dos seus órgãos e a normativa clássica de governança e, portanto, exigem formas novas e inovadoras de governança.

Portanto, destaca-se o motivo para o surgimento de uma governança tida como inteligente. Nesse sentido, a definição de governança passou a incluir a sociedade como um elemento fundamental nos processos governamentais, quando é afirmado que a "Governança" refere-se à relação entre indivíduos, grupos de interesse, instituições e prestadores de serviços nos negócios em andamento do governo (ODENDAAL, 2003).

Além de ferramentas, a nova governança envolve práticas e processos para que as pessoas participem do trabalho do governo (BINGHAM; NABATCHI; O’LEARY, 2005). Assim, conforme Rakodi (2001), há uma integração entre o Estado e a sociedade civil em diversos aspectos, não apenas nas regras e leis que compõem o governo. Complementando essa necessidade, Scholl e Scholl (2014) afirmaram, em seu estudo, que a autogovernança democrática nas economias de mercado do século 21 precisa desenvolver novos formatos institucionais e novos mecanismos para se manter a par da dinâmica sistêmica de uma 
sociedade global fortemente interconectada. Existe outro elemento que compõe e conecta essa relação, que é a tecnologia, ou seja, a junção desses elementos com a TIC pode ser um grande aliado da reforma de governo (GIL-GARCIA, 2012).

Dessa forma, há tendências claras da possibilidade de colaboração entre organizações, compartilhamento de informações, integração e participação da sociedade, o que Gil-Garcia (2012) afirma poder ser chamado de Estado inteligente. Esse Estado a que o autor se refere é um Estado que passa a funcionar para além das regras e normas e passa a ser prestador de informação, colocando a sociedade de modo geral como um agente participativo da gestão. Dessa forma, conforme Odendaal (2003), com a junção entre a tecnologia e a governança, o governo local estará em melhor posição para responder às necessidades locais de forma significativa e apropriada.

No que diz respeito ao aprimoramento, trazido ou esperado, pela governança inteligente em relação à sua versão anterior, dita como tradicional, é possível relatar os benefícios dessa nova abordagem, que já inicia com uma proposta diferente quando une sociedade, tecnologia, inovação e governo na boa condução de suas ações, viabilizando as demais ações inteligentes nas cidades, para que, assim, seja alcançada uma maior qualidade de vida.

A tecnologia é um grande elemento diferencial dessa nova visão, apesar de não ser o único elemento que constitui a governança moderna. Para Meijer (2016), a governança que se busca para uma cidade inteligente considera o uso de novas tecnologias para desenvolver arranjos inovadores de governança. Já para Chourabi et al. (2012), várias cidades se beneficiam do surgimento de TICs (tecnologias da informação e comunicação) que melhoram sua governança, resultando na governança inteligente. Essa união pode ser considerada, então, a base para a modernidade e o caminho para o crescimento da governança nos entes públicos, mas não consegue, de forma isolada, dar sustentação à governança de um governo inteligente.

Por meio de um estudo de caso, o trabalho de Shim e Eom (2008) identificou que essas TICs têm um grande potencial para a anticorrupção, em especial com a qualidade do controle interno e gerencial sobre comportamentos corruptos promovendo a responsabilidade e a transparência do governo. Essa funcionalidade da governança tem foco na prevenção de escândalos políticos na administração pública, convergindo, assim, para a segurança da 
população em relação à política, assim como na revisão de recursos omitidos do Estado e até mesmo na prevenção de atos ilícitos.

A proposta de caminho para o sucesso da governança inteligente fica muito clara na produção de Meijer (2016). O autor conclui que a combinação entre governança e tecnologia resulta em um melhor uso da informação e da comunicação; assim como os dados abertos e as mídias sociais criam uma governança colaborativa, mostrando, assim, a possibilidade de um elo colaborativo entre Estado e Sociedade. Afinal, o principal objetivo da governança da cidade inteligente não é apenas a utilização de novas tecnologias, mas sim a contribuição ao ambiente urbano, que deve ter foco na comunidade, na rede e nos participantes (MEIJER, 2016).

Reforçando a necessidade de elementos colaborativos em uma governança inteligente para além do uso da tecnologia, são necessárias a participação do cidadão (GIFFINGER et al., 2007), parcerias público-privadas (ODENDAAL, 2003) e a transparência aliada à prestação de contas (MooIJ, 2003), favorecendo-se, assim, a possibilidade de colaboração, a troca de dados, a integração de serviços e a comunicação (ODENDAAL, 2003). Gil-Garcia (2012) ainda relata que muitos são os benefícios com a integração dos governos, tais como a redução de duplicação de dados, esforços mais coordenados, eficiência, participação, transparência, redução de custos, eficácia de políticas e qualidade de serviço, ficando assim evidente a expressiva contribuição que a governança inteligente traz para a sociedade.

Deixando a figura da tecnologia de lado, Blanco (2015) afirmou que a governança de uma cidade é um processo de colaboração entre agentes governamentais e não governamentais, que, juntos, devem visar à construção de políticas públicas. Assim, Nesti (2018) conclui que a abordagem dada à governança das cidades vai depender das metas estabelecidas pelos representantes políticos, da atuação partidária entre partidos políticos e da troca de experiências entre governo, representações sociais e cidadãos.

Assim sendo, a governança inteligente pode ser entendida como uma prática crescente, ou seja, o elemento governança foi aprimorado ao longo do tempo, recebendo novas características que pudessem atender às necessidades atualizadas da população.

Em resumo, governança inteligente é a forma de atuação do governo com a participação da sociedade e o uso da tecnologia, de maneira a promover a participação do cidadão, parcerias público-privadas, transparência por meio da prestação de contas, redução 
de custos, interação entre as esferas do poder, esforços de governo direcionados e inovação no serviço público com vistas à sua maior qualidade.

\subsection{Diferença entre governança inteligente e governo inteligente}

Os termos governança inteligente e governo inteligente estão intimamente ligados, como afirma Scholl e Scholl (2014), ao mencionarem que o governo inteligente repousa sobre a base da governança inteligente. Por esse motivo, faz-se necessária uma distinção conceitual desses termos para a melhor compreensão do papel da governança inteligente.

Inicialmente, a partir de Gil-Garcia, Helbig e Ojo (2014), por um governo inteligente entende-se aquele que se utiliza da tecnologia e de várias estratégias de inovação para obter uma boa compreensão de suas comunidades e constituintes, usando essas ferramentas para avaliar com exatidão situações ou pessoas; mostrar poderes de julgamento aguçados; e, então, tomar decisões e responder de maneira rápida ou eficaz. Dessa forma, ser um governo mais inteligente parece exigir uma integração da informação, tecnologia e inovação nas atividades governamentais. Conforme Nam e Pardo (2014), uma métrica para a avaliação desse tipo de

governo se dá por meio de quatro elementos, sendo eles eficiência, eficácia, transparência e colaboração.

Já a governança inteligente é a união de princípios, fatores e competência que, juntos, formam uma governança capaz de atender às necessidades da sociedade do conhecimento (WILlKE, 2007). Conforme Bingham, Nabatchi e O’Leary (2005), esses novos processos de governança podem ajudar os administradores públicos a construir parcerias com cidadãos e partes interessadas fazendo parte do trabalho do governo. Para o Parlamento Europeu, Smart Governance é entendida como uma governança intramunicipal e intercidades, incluindo serviços e interações que ligam e, quando relevante, integram organizações públicas, privadas, civis e da comunidade, para que a cidade possa funcionar de forma eficiente e efetiva como um organismo. Para isso, utiliza-se da tecnologia da infraestrutura, hardware e software, alimentada por dados. Os links internacionais, nacionais e do interior também são importantes, uma vez que uma cidade inteligente pode ser descrita como um centro globalmente conectado em rede. Isso implica em parcerias públicas, privadas e civis e na 
colaboração com diferentes partes interessadas trabalhando em conjunto na busca de objetivos inteligentes em nível de cidade (EUROPEAN PARLAMIENT, 2014).

Sendo assim, o governo inteligente é o responsável, por meio da integração entre informação, tecnologia e inovação, pela implementação das atividades requeridas por meio da governança inteligente (GIL-GARCIA; HELBIG; OJO, 2014). Já a governança inteligente é tida como a base para um governo inteligente, aberto e participativo (SCHOLL; SCHOLL, 2014).

Portanto, conclui-se que a governança inteligente é formada por elementos que buscam atender à necessidade da sociedade atual, e o governo inteligente é responsável pela implementação e construção de um espaço capaz de proporcionar a sua existência e manutenção, estando aberto aos recursos da tecnologia e da sociedade, entre outros aspectos.

\subsection{Considerações sobre governo aberto (open government) e governo eletrônico (e- government)}

Aqui são considerados alguns elementos que, de forma direta ou indireta, auxiliam o processo de governança para uma cidade inteligente. Dessa forma, o intuito desta seção é compreender o que são esses elementos, bem como verificar como eles são capazes de auxiliar no alcance de uma governança na perspectiva de uma cidade inteligente, visto que, conforme Meijer e Bolívar (2015), a pesquisa sobre governança de cidade inteligente pode se beneficiar de estudos anteriores sobre fatores de sucesso e fracasso para o governo eletrônico.

A figura do governo aberto é uma métrica que tem como objetivo a transparência das ações governamentais por meio da abertura de dados, fazendo com que a população seja conhecedora da forma de trabalho de seus respectivos governos.

Uma iniciativa de governo aberto, que mostra a sua importância, é exposta na pesquisa de Bertot et al. (2014). Nesta, apresenta-se a ferramenta Data.gov, que é responsável por fornecer acesso direto a uma grande quantidade de informações públicas nos Estados Unidos. Salienta-se que, por meio da relação entre Big Data e Open Data, haverá uma grande quantidade de informações de forma aberta, garantindo um conjunto de dados acessíveis sobre as atividades do governo e suas ações sociais. 
Em 2009, foi publicado nos Estados Unidos o memorando que determina diretrizes para o governo aberto. Essas diretrizes definiram princípios, sendo eles: transparência, participação e colaboração (ORSZAG, 2009). Esse memorando retrata o caso dos Estados Unidos. Contudo, pode-se entender que existem alguns caminhos necessários a serem observados e regras a serem seguidas, pois um governo bom e aberto não é o mesmo que um reality show, que transmite todos os movimentos e conversas realizadas. Pelo contrário, um bom governo requer certos limites para esse tipo de transparência, pois há implicações para a estratégia política (COGLIANESE, 2009).

Quando questionados sobre governo eletrônico, Gil-García e Pardo (2005) determinam que este seria um governo com o uso intensivo ou generalizado de tecnologias da informação aplicadas à prestação de serviços públicos, à melhoria da eficácia gerencial e à promoção de valores e mecanismos democráticos. Dois benefícios principais podem ser evidenciados na percepção desses autores, a saber: (1) maior eficiência operacional, reduzindo custos e aumentando a produtividade; e (2) melhor qualidade de serviços prestados por agências governamentais.

Na visão de Lam (2005), outro benefício trazido pelo governo eletrônico é a centralização, coesão e continuidade dos serviços ofertados aos usuários. Sobre centralização e coesão e a consequente continuidade, Basu (2004) retrata que o termo e-governance pode ser entendido como um elemento simplificador da governança entre todas as partes; governo, cidadãos e empresas. Não se trata, portanto, de um mero site do governo na internet. Em vez disso, consiste na possibilidade de, por meio do uso de TIC, fazer essa conexão entre as partes mencionadas. $\mathrm{O}$ autor assemelha a boa governança à governança eletrônica. Sendo assim, ambas podem ser vistas como um exercício de autoridade econômica, política e administrativa para melhor administrar os negócios de um país em todos os níveis. Nessa ótica, Bertot et al. (2014) afirmam que uma base de dados grande e aberta (Big and Open Data) é essencial, não só para o desenvolvimento do governo eletrônico, como também para a construção de um governo aberto e transparente, assim como para proporcionar uma boa interação entre governos, cidadãos e o meio empresarial, sendo a participação da sociedade o principal propósito. "Em pesquisas recentes na área de governo eletrônico, há um foco claro no empoderamento dos cidadãos por meio do governo eletrônico" (AL-RABABAH; ABUSHANAB, 2010, p. 2). 
Já Chun et al. (2010) tratam do governo eletrônico por meio de quatro estágios, descrevendo os padrões de interação dos governos digitais com o público: o primeiro estágio do governo eletrônico se concentra na "presença digital", com sites simples e informações básicas. O segundo estágio passa para a interação, contudo, simples, entre governos e com cidadãos, empresas e outras agências governamentais por meio de contatos por e-mail e formulários interativos, que podem fornecer dinamicamente as informações necessárias. O terceiro estágio dessa evolução fornece serviços de transação on-line, como renovação de licença, pedidos de permissão e pagamentos de impostos. O último estágio se dá com o governo promovendo a governança compartilhada para transformar a forma como o governo opera em termos de fluxo de informações contínuo e tomada de decisão colaborativa.

Pode-se concluir, então, que o papel do governo eletrônico é o de auxiliar na construção da governança inteligente, tornando, assim, o governo inteligente por meio do uso da tecnologia. Essa conclusão pode ser reafirmada com outra contribuição dada para o entendimento do papel do governo eletrônico na governança, que é a da pesquisa de Shim e Eom (2008), que o retrata como uma ferramenta eficaz para a redução da corrupção, promovendo a boa governança, reduzindo os comportamentos de corrupção externamente, aprimorando os relacionamentos com os cidadãos internamente e monitorando com mais eficiência os comportamentos dos funcionários com mais eficiência.

Sendo assim, a união do governo aberto com o governo eletrônico é o objetivo inteligente da governança, que inclui a transparência e os dados abertos usando as TICs e o governo eletrônico na tomada de decisões participativas e nos serviços eletrônicos cocriados, como aplicativos, por exemplo (EUROPEAN PARLAMIENT, 2014).

Entende-se, então, que a figura do governo aberto é responsável por disponibilizar o acesso a uma grande quantidade de dados, responsável pela prestação de contas de forma transparente à sociedade (FELIX JÚNIOR et al., 2020b). Já o governo eletrônico é o meio pelo qual o cidadão ou as demais esferas que necessitam de informações passam a ter acesso, e, além disso, é uma ferramenta capaz de prestar serviços à comunidade (FELIX JÚNIOR et al., 2020b).

Portanto, boas práticas de governança por meio de plataformas de governo eletrônico podem ser instrumentos adequados para fortalecer os resultados das políticas de cidades inteligentes (ROTTA et al., 2019). Ambos os casos contribuem para o desenvolvimento da 
governança na perspectiva de uma cidade inteligente, trazendo o uso da tecnologia para a interação com a sociedade e o meio empresarial, assim como buscando a ligação entre as esferas do governo.

\section{Aspectos da revisão sistemática da literatura}

Dando prosseguimento à explanação sobre elementos que dialogam sobre a governança inteligente, esta seção apresenta os dados das produções científicas coletados por meio da base Scopus $®$ e gerenciados com o apoio do Software VOSviewer ${ }^{\circledR}$. São destacados os elementos numéricos capazes de direcionar os principais autores, países, palavras-chave e produções mais citadas que tratam governança inteligente; e os elementos textuais representados por conceitos, tendências de pesquisa, elementos vinculados à governança inteligente e uma agenda de pesquisas futuras sobre esse tema.

\subsection{Elementos numéricos}

Esta apresentação numérica se inicia com a evolução da produção ao longo dos anos, conforme a Figura 1.

\section{Figura 1 - Evolução da produção em governança inteligente}

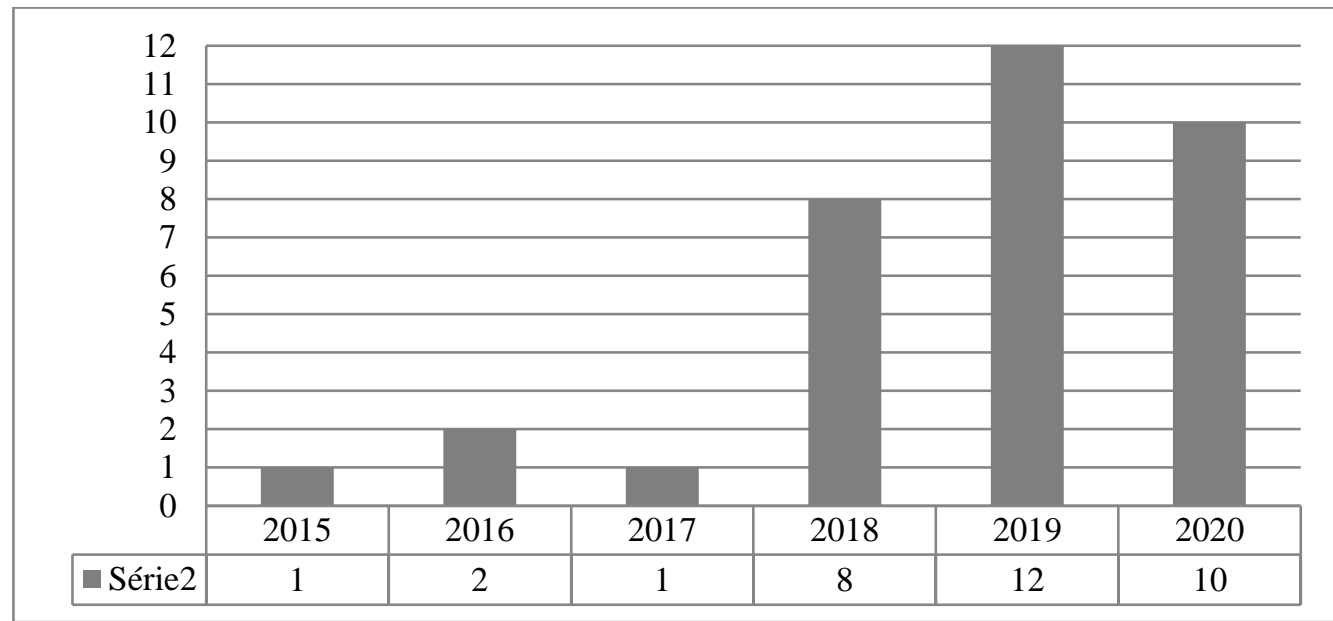

Fonte: Elaborado pelos autores (2020).

Destaca-se que o parâmetro de busca realizado nesta pesquisa vai de 2009 até 2020. Porém, apenas em 2015 surgem os primeiros estudos utilizando a terminologia "smart 
governance" (governança inteligente), e que apenas nos últimos três anos a produção científica se intensifica, evidenciando a relevância e atualidade da palavra-chave selecionada para discussão da governança da cidade inteligente, apresentando os destaques mais atuais.

Em relação ao número de artigos por países, aqueles que possuíam mais de um artigo publicado foram apontados na Tabela 1. Ficam em evidência Holanda e Espanha, tanto em quantitativo de artigos como em relação aos trabalhos mais citados.

\section{Tabela 1 - Países com maior número de artigos publicados}

\begin{tabular}{ccc}
\hline Países & $\mathbf{N}^{\mathbf{0}}$. de artigos & $\mathbf{N}^{\mathbf{0}}$. de citações \\
\hline Holanda & 8 & 115 \\
Espanha & 7 & 75 \\
China & 4 & 44 \\
Brasil & 4 & 53 \\
Itália & 4 & 8 \\
Áustria & 3 & 65 \\
Reino Unido & 3 & 34 \\
Alemanha & 2 & 68 \\
Noruega & 2 & 6 \\
Estados Unidos & 2 & 62 \\
\hline
\end{tabular}

Fonte: Elaborado pelos autores, a partir de dados extraídos do Software VOSviewer (2020).

Com base no Ranking IESE Cities in Motion Index (CIMI), com resultados do ano de 2020, que apresenta o ranking das cidades inteligentes mais desenvolvidas do mundo em 2019, apenas o Reino Unido e os Estados Unidos, que estão entre os países com maior número de publicação, conforme Tabela 1, estão entre os 10 países com melhor ranking em governança (BERRONE; RICART, 2020). Portanto, as publicações científicas nos países podem não estar sendo associadas às ações práticas dos governos, seja por desconsiderações dos governos ou pela falta de envolvimento entre academia e governo.

Em relação aos autores, foram destacados aqueles que possuíam mais de um trabalho produzido e publicado, sendo apresentados, na Tabela 2, o quantitativo de produção e as citações dos pesquisadores identificados nesta pesquisa e indicados como importantes referências quando da discussão da temática da governança nas cidades inteligentes. 
Tabela 2 - Pesquisadores com maior número de artigos

\begin{tabular}{lcc}
\hline \multicolumn{1}{c}{ Pesquisadores } & $\mathbf{N}^{\mathbf{0}}$. de artigos & $\mathbf{N}^{\mathbf{0}}$ de citações \\
\hline Geertman, S. & 4 & 37 \\
Parycek, P. & 3 & 65 \\
Pereira, G. V. & 3 & 65 \\
Bolívar, M. P. R. & 3 & 53 \\
Nesti, G. & 3 & 8 \\
Lin, Y. & 2 & 41 \\
Meijer, A. & 2 & 44 \\
Jiang, H. & 2 & 5 \\
Witte, P. & 2 & 5 \\
\hline Fonte: Elaborado pelos autores, a partir de dados extraídos do Software VOSviewer (2020).
\end{tabular}

Fonte: Elaborado pelos autores, a partir de dados extraídos do Software VOSviewer (2020).

Com o maior número de produções, destaca-se o trabalho de Geertman, que possui pesquisa desde 2015 nessa temática.

São identificadas algumas relações de coautoria entre os pesquisadores apontados na Tabela 2. Geertman desenvolveu parcerias de trabalho com Jiang e Witte. Dentre elas, a que discute a governança inteligente do ponto de vista da administração pública e a governança na perspectiva do planejamento urbano apresentando o conceito de governança urbana inteligente pelos autores Jiang, Geertman e Witte (2019). Geertman também desenvolveu estudos com Meijer e Lin.

Meijer ainda produz trabalhos com Bolívar, em busca das dimensões que versam sobre a governança inteligente e a percepção dos governos locais europeus sobre tais elementos (Bolívar; MEIJER, 2016).

Já Parycek e Pereira, dentre a produção selecionada, aparecem sempre em colaboração. Identificou-se que ambos são da Danube University Krems, na Austria, e, junto com os demais coautores, investigaram o caso do projeto SmartGov, que mapeia problemas reais e auxilia na tomada de decisão (PEREIRA et al., 2018a); também realizaram a análise empírica de como as TICs podem promover a governança colaborativa e aumentar a participação e o envolvimento no governo (PEREIRA et al., 2018b); e a revisão da literatura apontando definições e relações entre governança inteligente e conceitos como governo inteligente e eletrônico (PEREIRA et al., 2017). 
No Quadro 4, destacam-se os 10 trabalhos mais citados, sendo indicados na produção de estudos em governança da cidade inteligente. A pesquisa de Ruhlandt (2018) fica evidente com o maior número de citações, apesar de este autor não figurar entre os pesquisadores com maior número de artigos. O destaque dessa produção é dado pela sua capacidade em conceituar elementos das cidades inteligentes, sendo base para o desenvolvimento de outras pesquisas.

\section{Quadro 4 - Top 10 dos artigos mais citados}

\begin{tabular}{|c|c|c|c|}
\hline Autores e ano & Título & Nome do periódico & Citações \\
\hline $\begin{array}{c}\text { Ruhlandt } \\
(2018)\end{array}$ & $\begin{array}{l}\text { The governance of smart cities: a systematic literature } \\
\text { review. }\end{array}$ & Cities & 62 \\
\hline Artmann et al. & $\begin{array}{l}\text { How smart growth and green infrastructure can } \\
\text { mutually support each other - A conceptual } \\
\text { framework for compact and green cities }\end{array}$ & Ecological Indicators & 42 \\
\hline $\begin{array}{c}\text { Meijer e } \\
\text { Bolívar (2016) }\end{array}$ & $\begin{array}{l}\text { Smart Governance: using a Literature Review and } \\
\text { Empirical Analysis to Build a Research Model. }\end{array}$ & $\begin{array}{c}\text { Social Science } \\
\text { Computer Review }\end{array}$ & 41 \\
\hline $\begin{array}{l}\text { Pereira et al. } \\
\quad(2017)\end{array}$ & $\begin{array}{l}\text { Increasing collaboration and participation in smart } \\
\text { city governance: a cross-case analysis of smart city } \\
\text { initiatives. }\end{array}$ & $\begin{array}{l}\text { Information } \\
\text { Technology for } \\
\text { Development }\end{array}$ & 38 \\
\hline $\begin{array}{l}\text { Lin, Zhang e } \\
\text { Geertman } \\
\text { (2015) }\end{array}$ & $\begin{array}{l}\text { Toward smart governance and social sustainability } \\
\text { for Chinese migrant communities. }\end{array}$ & $\begin{array}{l}\text { Journal of Cleaner } \\
\text { Production }\end{array}$ & 29 \\
\hline $\begin{array}{c}\text { Webster e } \\
\text { Leleux (2018) }\end{array}$ & $\begin{array}{l}\text { Smart Governance: opportunities for technologically- } \\
\text { mediated citizen co-production. }\end{array}$ & Information Polity & 27 \\
\hline Lin $(2018)$ & $\begin{array}{l}\text { A comparison of selected Western and Chinese smart } \\
\text { governance: the application of ICT in governmental } \\
\text { management, participation and collaboration. }\end{array}$ & $\begin{array}{l}\text { Telecommunications } \\
\text { Policy }\end{array}$ & 12 \\
\hline $\begin{array}{c}\text { Palomo- } \\
\text { Navarro e } \\
\text { Navío-Marco } \\
(2018) \\
\end{array}$ & $\begin{array}{l}\text { Smart city networks' governance: the Spanish smart } \\
\text { city network case study }\end{array}$ & $\begin{array}{l}\text { Telecommunications } \\
\text { Policy }\end{array}$ & 11 \\
\hline $\begin{array}{l}\text { Tahir e Malek } \\
\text { (2016) }\end{array}$ & $\begin{array}{l}\text { Main criteria in the development of smart cities } \\
\text { determined using analytical method. }\end{array}$ & Planning Malaysia & 8 \\
\hline $\begin{array}{l}\text { De Guimarães } \\
\text { et al. }(2020)\end{array}$ & $\begin{array}{l}\text { Governance and quality of life in smart cities: towards } \\
\text { sustainable development goals }\end{array}$ & $\begin{array}{l}\text { Journal of Cleaner } \\
\text { Production }\end{array}$ & 7 \\
\hline
\end{tabular}

Fonte: Elaborado pelos autores, a partir de dados da pesquisa extraídos da Scopus® (2020).

Os trabalhos mais citados destacam temas como governança da cidade inteligente (RUHLANDT, 2018); cidades inteligentes compactas e verdes (ARTMANN et al., 2019); dimensões da governança inteligente e governos locais europeus (MEIJER; BOLÍVAR, 2016); governança inteligente, governo inteligente e eletrônico (PEREIRA et al., 2017); migração, governança inteligente e sustentabilidade social (LIN; ZHANG; GEERTMAN, 2015); governança de cidades inteligentes, envolvimento dos cidadãos na coprodução da prestação 
de serviços e tomada de decisões (WEBSTER; LELEUX, 2018); estrutura comparada de governança inteligente em diferentes contextos (LIN, 2018); estudo de redes de governança com base em conselheiros (PALOMO-NAVARRO; NAVÍO-MARCO, 2018); requisitos da cidade inteligente e metodologia Analytic Hierarchy Process (AHP) (TAHIR; MALEK, 2016); governança e qualidade de vida (DE GUIMÃRAES et al., 2020).

\subsection{Elementos textuais}

Esta seção apresenta os conceitos identificados, as tendências de pesquisa, os elementos e a agenda de pesquisas futuras em governança inteligente.

\subsubsection{Conceitos}

Nos trabalhos selecionados, foram observados conceitos da governança inteligente ao longo do resumo das pesquisas. Diversos pesquisadores adotam conceito que envolve o uso da tecnologia e a abordagem junto aos atores sociais, em especial o cidadão, como apresentado a seguir.

Pereira et al. (2018b) afirmam que a governança inteligente utiliza-se de TIC para melhorar a tomada de decisão por meio de uma melhor colaboração entre as diferentes partes interessadas, incluindo governo e cidadãos, sendo as ferramentas baseadas em TIC, como mídias sociais e abertura de dados, fatores que aumentam o envolvimento dos cidadãos e apoiam o desenvolvimento de uma nova governança. Webster e Leleux (2018) complementam, afirmando que as TICs estão integradas em estratégias de participação cidadã e coprodução de serviços e políticas públicas.

Ben Yahia et al. (2019) seguem a mesma linhagem conceitual, considerando a governança inteligente como uma rede colaborativa de agências governamentais e partes interessadas externas, incluindo cidadãos e a interação com a tecnologia. Ranchod (2020) determina que a governança inteligente visa melhorar a gestão urbana por meio de tomadas

de decisão baseadas em dados aprimorados e inclusão e participação proporcionais dos atores cívicos nesse processo.

Nesti (2020) defende a reorganização governamental com base na atuação dos diversos atores, afirmando que a governança inteligente envolve a adoção de uma nova 
abordagem baseada em experimentação, colaboração com todos os atores locais e reorganização das estruturas governamentais existentes.

E, por fim, dentre as conceituações que envolvem a tecnologia e a sociedade, Silva e Fernandes (2020) apresentam a informação como um elemento crucial nas smart cities, que possibilita a boa governança inteligente, destacando a participação e a transparência.

Em um conceituo puramente tecnológico, Martínez (2019) define que a governança inteligente é um novo modelo de governança que está surgindo como resultado do uso cada vez mais difundido de algoritmos na administração pública.

Em relação ao aspecto da confiança e anticorrupção, Yolles (2019) apresenta que a governança inteligente está relacionada à capacidade das administrações políticas de obter confiança e à confiança do público.

Por último, Jiang, Geertman e Witte (2019) apresentam o conceito da governança das cidades inteligentes em duas perspectivas. Na primeira, do ponto de vista da administração pública, a governança inteligente enfatiza a importância das ferramentas baseadas em tecnologia na transformação das instituições governamentais. Na segunda, de uma perspectiva do planejamento urbano, a governança de cidades inteligentes concentra-se na interação da instituição com os desafios espaciais.

Ao observar os conceitos presentes nas pesquisas, identifica-se que as conceituações possuem elementos também encontrados nas palavras-chave, conforme Tabela 3:

\section{Tabela 3 - Top 10 das palavras-chave com maior representatividade}

\begin{tabular}{ccc}
\hline Palavras-chave & Ocorrência & Capacidade de ligação das palavras \\
\hline Governança inteligente & 24 & 83 \\
Cidade inteligente & 19 & 95 \\
\hline Abordagem de governança & 7 & 53 \\
Desenvolvimento urbano & 4 & 34 \\
\hline Desenvolvimento sustentável & 4 & 22 \\
Tomando uma decisão & 4 & 19 \\
Governança colaborativa & 4 & 9 \\
Tecnologia da informação e comunicação & 3 & 35 \\
Participação local & 3 & 34 \\
Participação cidadã & 3 & 28 \\
\hline
\end{tabular}

Fonte: Elaborado pelos autores, a partir de dados da pesquisa extraídos do Software VOSviewer (2020). 
Portanto, conforme a Tabela 3, as palavras-chave identificadas nos artigos selecionados podem ser utilizadas para pesquisas futuras para identificação mais precisa de estudos relacionados à governança nas cidades inteligentes, em especial à governança inteligente, à cidade inteligente, ao desenvolvimento urbano, à tecnologia da informação e comunicação e à participação local e cidadã.

Em síntese, conclui-se que o conceito de governança inteligente se dá pela associação do uso da tecnologia com o envolvimento dos atores locais, em especial o cidadão, para definição mais acertada das políticas públicas, coprodução de serviços e práticas de governo, gerando uma maior confiança na administração pública.

\subsubsection{Tendências de pesquisa e elementos da governança inteligente}

Por meio do software VOSviewer, foi desenvolvido um mapa de palavras e clusters com base nas publicações selecionadas nesta etapa. O mapa de palavras apresenta os principais termos envolvidos nas pesquisas. Foram identificados 1.076 termos e a análise considerou os termos que se repetiam no mínimo 7 vezes, reduzindo a 35 termos mais relevantes, sendo excluídos elementos de natureza exclusivamente científica, como article, use, application, outcome, concept, paper, study, research e role.

No Quadro 5, encontram-se os clusters que são agrupamentos de termos que indicam forte ligação entre si, estando aglomerados em uma mesma discussão. Dessa forma, podemse entender tais agrupamentos como as tendências de pesquisas relacionadas ao tema governança em cidades inteligentes. 
Quadro 5 - Relação de clusters

\begin{tabular}{|c|c|c|c|}
\hline Cluster 1 & Cluster 2 & Cluster 3 & Cluster 4 \\
\hline Utilização (application) & $\begin{array}{c}\text { Responsabilidade } \\
\text { (accountability) }\end{array}$ & $\begin{array}{c}\text { Meio ambiente } \\
\text { (environmet) }\end{array}$ & Cidade (city) \\
\hline Cidadão (citizen) & Dados (data) & Vida (life) & $\begin{array}{c}\text { Desenvolvimento } \\
\text { (development) }\end{array}$ \\
\hline Colaboração (collaboration) & Informação (information) & Processo (process) & Framework \\
\hline $\begin{array}{c}\text { Tecnologia da informação e } \\
\text { comunicação (ICT) }\end{array}$ & Participação (participation) & Qualidade (quality) & $\begin{array}{c}\text { Cidade verde } \\
\text { (green city) }\end{array}$ \\
\hline Contexto (contexto) & Sistema (system) & $\begin{array}{c}\text { Cidade inteligente } \\
\text { (smart city) }\end{array}$ & \\
\hline $\begin{array}{c}\text { Governança (governance) } \\
\text { Governo (government) }\end{array}$ & Transparência (transparency) & $\begin{array}{c}\text { Tecnologia } \\
\text { technology) }\end{array}$ & \\
\hline $\begin{array}{c}\text { Governança de cidade } \\
\text { inteligente (smart city } \\
\text { governance) }\end{array}$ & & & \\
\hline $\begin{array}{c}\text { Governança inteligente (smart } \\
\text { governance) }\end{array}$ & & & \\
\hline
\end{tabular}

Fonte: Elaborado pelos autores, a partir de dados da pesquisa extraídos do Software VOSviewer (2020).

- O cluster 1 é o que possui o maior agrupamento de termos e representa os trabalhos que discutem a governança inteligente e elementos como a tecnologia, a colaboração e o cidadão, assim como o contexto.

- O cluster 2 destaca outros elementos da governança, em uma abordagem que trata da transparência, por meio da informação em sistemas que são gerados por dados, elementos que colaboram para a participação dos atores sociais e trazem maior responsabilidade para o poder público.

- O cluster 3 relaciona os aspectos da qualidade de vida e do meio ambiente dentro das cidades inteligentes, destacando mais uma vez a tecnologia dentro desse processo.

- O cluster 4 destaca novamente elementos da sustentabilidade, voltado para pesquisas que interagem com modelos de cidades inteligentes sustentáveis.

Dentro dos clusters, destacam-se os elementos que colaboram para o desenvolvimento da governança na cidade inteligente, mas também ficam evidentes os aspectos ambientais que as pesquisas em cidades inteligentes vêm destacando.

Como o objetivo desta pesquisa é conhecer elementos que colaborem com a governança inteligente (smart governance), foi destacado, na Figura 3, extraída do software VOSviewer, apenas esse tema e suas ligações com os elementos com que dialoga. 
Figura 3 - mapa de clusters destacando a relação de elementos da governança inteligente

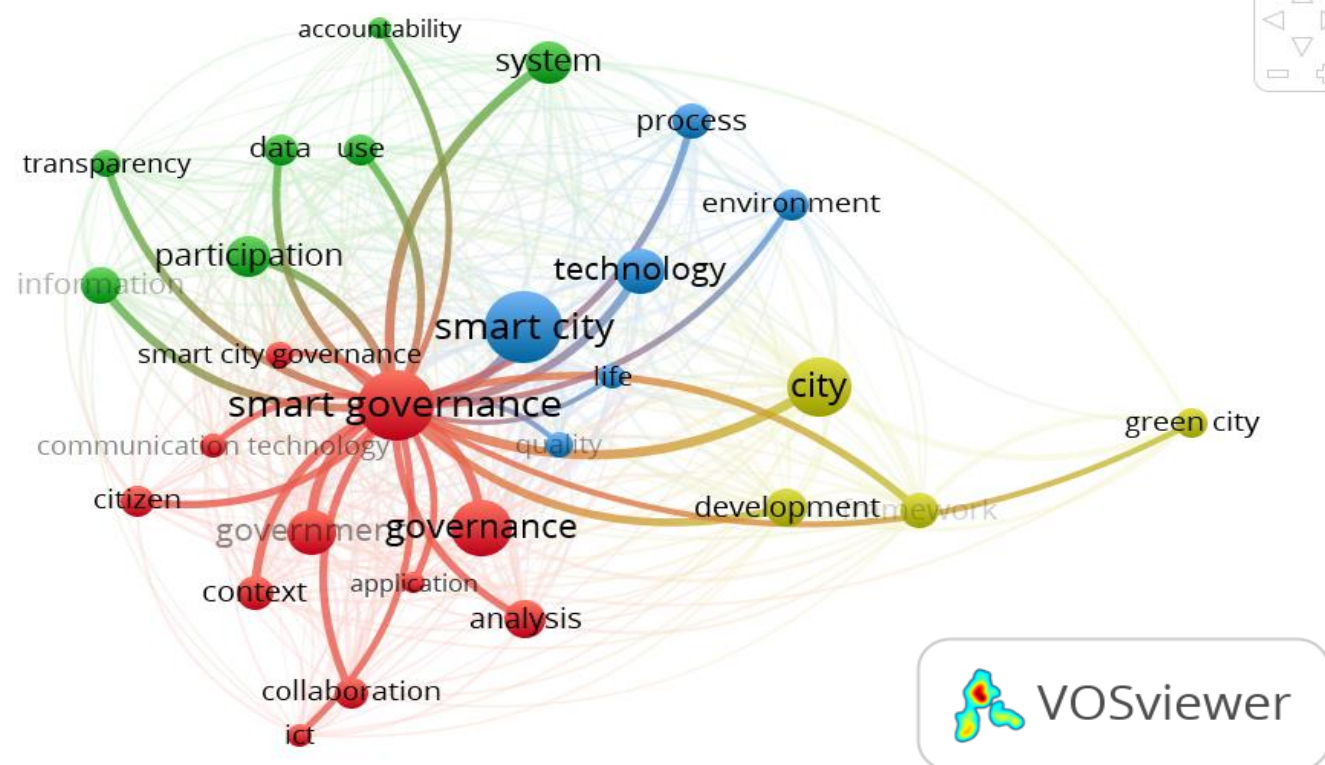

Fonte: Elaborado pelos autores, a partir de dados da pesquisa extraídos do Software VOSviewer (2020).

Com base nos trabalhos selecionados neste levantamento, a governança inteligente se relaciona com diversos termos, destacando-se desenvolvimento, dados, transparência, participação, contexto, cidadão, colaboração, desenvolvimento, tecnologia da informação e comunicação, e meio ambiente. Foram extraídas algumas colaborações teóricas sobre tais elementos em relação à governança inteligente para evidenciar como se dá o diálogo entre o termo governança inteligente e suas ligações.

Os termos cidade verde (green city) e meio ambiente (environment) são apresentados na proposta de estudo de Artnanm et al. (2019), trazendo a governança inteligente como um elemento importante para o desenvolvimento das cidades sustentáveis e inteligentes.

O elemento contexto (context) é destacado por Lin (2018), concluindo que há uma falta de estudos comparativos de governança inteligente em diferentes contextos institucionais, sendo este seu objetivo de pesquisa. Já a pesquisa de Ruhlandt (2018) detecta, em seu estudo conceitual, que há variações substanciais em termos de fatores contextuais. Ainda sobre contexto, Jiang, Geertman e Witte (2019) concluem que a governança urbana inteligente deve considerar o contexto socioespacial específico para uma melhoria da 
compreensão dos desafios urbanos associados às cidades inteligentes, obtendo, assim, uma maior contribuição para uma governança adequada e inteligente.

A responsabilidade (accountability) entra em discussão como uma consequência da governança inteligente, pois Nesti (2020) defende que o processo de desenvolvimento da governança deve ser conduzido por atores públicos, aumentando a legitimidade democrática e a responsabilidade, garantindo, assim, resultados tangíveis para os cidadãos. A responsabilidade também é destacada por Gil, Cortés-Cediel e Cantador (2019), que definem que, por meio das plataformas eletrônicas, é gerada uma maior participação cidadã nos processos de tomada de decisão, objetivando uma melhor prestação de informações e serviços, reforçando a transparência e a responsabilidade, bem como a credibilidade.

Os elementos colaboração, participação, transparência, tecnologia da informação e comunicação são discutidos dentro das pesquisas em um espaço compartilhado. Conforme Nesti (2019), a governança inteligente envolve a adoção de uma nova abordagem baseada em experimentação, colaboração com todos os atores locais e reorganização das estruturas governamentais existentes. Da mesma forma, Ben Yahia et al. (2019) destacam que governar uma cidade inteligente é promover um ambiente eficaz de colaboração no governo e implica a formulação de políticas para construir novas colaborações humanas internas e externas.

Sifah et al. (2020) apresentam a governança como uma forma de garantir uma tomada de decisão mais inteligente, abertura e participação colaborativa de todas as entidades envolvidas como ajuda a minimizar o uso de recursos, reduzir o consumo e os custos. Como forma de comunicação para a colaboração, Rotta et al. (2019) apresentam as plataformas eGov como espaços digitais onde cidadãos e agentes públicos interagem e colaboram.

Pereira et al. (2018b) e Pereira et al. (2017) reafirmam o poder da tecnologia nesse processo, pois as TICs têm um papel importante no apoio ao compartilhamento de informações e integração entre agências governamentais e partes interessadas externas, incluindo cidadãos, especialmente.

Já Silva e Fernandes (2020) destacam a participação e a transparência como elementos relevantes para o bom desempenho da governança.

Contudo, Nesti e Graziano (2019) mostram que as cidades inteligentes são baseadas em princípios de representação democrática, mas a ligação entre as instituições políticas e o 
público em geral não está totalmente desenvolvida devido à falta de mecanismos que promovam verdadeiramente a participação e a voz dos cidadãos.

\subsubsection{Agenda de pesquisas futuras}

Neste tópico, buscou-se evidenciar, em meio aos artigos analisados, uma agenda de pesquisa, demonstrando as lacunas para realização de futuros estudos acerca da temática. Nesse sentido, destacam-se, inicialmente, os estudos de Tomor et. al (2019) e Romanelli (2020), os quais relacionam lacunas de pesquisa no que tange ao uso das tecnologias de informação (TICs) na governança das cidades inteligentes. No primeiro estudo, os autores refletem que pesquisas futuras devem partir de uma compreensão contextual de governança inteligente, como diferentes cenários em diferentes prioridades urbanas e circunstâncias que produzem dinâmicas diferentes de governança colaborativa apoiada pelas TICs. Sobre a governança inteligente, Jiang, Geertman e Witte (2019) relatam que seu estudo fornece os primeiros passos nas pesquisas envolvendo a governança inteligente e a governança urbana. Entretanto, recomendam que haja maior aprofundamento dessa temática. Já na perspectiva de Romanelli (2020), deve ser aprofundada a investigação sobre o uso da tecnologia na definição de estratégia e planejamento urbano sustentável, contando com uma visão inteligente e com uma visão orientada para a comunidade como um caminho futuro para o crescimento urbano, inclusivo e socialmente responsável e impulsionado pelo homem.

O estudo de Ben Yahia et al. (2019) também reflete uma preocupação social, tendo em vista que os autores destacam, em seu estudo, a necessidade do desenvolvimento de pesquisas que abordem a proximidade social entre os atores (cidadãos) que compõem determinada smart city, evidenciando seus perfis, emoções e interesses, a fim de levar em conta, também, suas motivações para se envolverem na rede colaborativa, analisando, ainda, o contexto colaborativo nos quais estão inseridos. No que tange à rede colaborativa, Lin (2018) enfatiza que a realização de pesquisas para compreender as diversas formas, estratégias, arranjos e resultados da governança inteligente em diferentes locais e contextos torna-se necessária, buscando explorar ligações entre governança inteligente, participação e colaboração. 
Já os estudos de Gil, Cortés-Cediel e Cantador (2019) e Neis, Zielstra e Zipf (2012) trazem, como lacuna de pesquisa, a participação do cidadão na governança inteligente, sendo que a primeira investigação traz a necessidade de entender o que impulsiona um grande número de pessoas a participar de plataformas eletrônicas, e de onde vem a motivação para aumentar a participação. Seguindo a mesma ótica, o trabalho de Neis, Zielstra e Zipf (2012) demonstra que são necessárias mais evidências nos resultados da participação em plataformas de mídia digital em um conjunto maior de casos como soluções para desafios do mundo real.

Para Bolívar (2018), no que tange à governança inteligente, existem algumas questões que podem vir a impulsionar novas investigações, como padrões eficientes ou ineficientes de governança de cidades inteligentes; definição de estratégias por parte dos legisladores no âmbito do quadro de cidades inteligentes; e se os mesmos são forçados a implementar estruturas para tornar suas cidades inteligentes. Corroborando essa perspectiva, Pereira et al. (2017) ressaltam que compreender as consequências não intencionais das iniciativas de cidades inteligentes é outro aspecto que deve ser explorado em pesquisas futuras.

Em outra investigação, Bolívar (2018) reflete outros questionamentos que podem impulsionar a realização de novas pesquisas, entre estes: as cidades inteligentes estão em um estágio inicial de desenvolvimento no caminho para e-participação? A característica qualitativa de "inteligente" é apenas uma imagem de marca para a cidade? Os cidadãos são promovidos e preparados para participar da gestão da cidade? O que são os incentivos para os cidadãos participarem com os governos locais? E em que condições?

Ainda no que tange à governança inteligente, o estudo de Silva e Fernandes (2020) recomenda que, em futuras pesquisas, sejam realizados estudos com amostras qualificadas de diferentes cidades, com o intuito de construir um modelo de referência, bem como definir ações que podem ser usadas para melhorar a eficácia das práticas de smart governance, por meio das técnicas de inferência estatística. Para Razaghi e Finger (2018), o aprofundamento em pesquisas com a referida temática é necessário para fornecer informações que podem ajudar a moldar a governança de cidades inteligentes.

De Guimarães et al. (2019) apontam lacunas de pesquisa em relação à governança pública que se referem, sobretudo, a questões relacionadas à identificação de outros fatores 
que influenciam o impacto da governança pública sobre a qualidade de vida no contexto das cidades inteligentes. Além disso, os autores destacam como aspecto importante a investigação dos programas e políticas que os governos de cidades inteligentes usam para operacionalizar as ações de transparência, colaboração, participação e parceria, comunicação e responsabilidade, a fim de melhorar a qualidade de vida. Outra perspectiva para o desenvolvimento de novos estudos refere-se à análise em outros contextos regionais, uma vez que o contexto estrutural da cidade é um fator relevante para as práticas de cidades inteligentes.

Outro estudo que apresentou lacunas de pesquisa foi a investigação de Artmann et al. (2017), que enfatiza a compreensão das oportunidades e necessidades de ações para abordar cidades inteligentes no contexto verde. Além desta, ressalta-se o estudo de Nesti (2019), que recomenda aprofundamento sobre os desafios teóricos, metodológicos e empíricos que podem dificultar a implementação de estratégias de igualdade de gênero em cidades inteligentes, com o objetivo de avaliar se a inclusão da igualdade de gênero está se tornando parte das estratégias inteligentes adotadas pelo município.

\section{Conclusões}

Este estudo se preocupou em evidenciar elementos que colaboram para o desenvolvimento da governança inteligente, tipo de governança direcionada às cidades inteligentes ou àquelas que possuem projetos para se tornarem cidades inteligentes. Para o alcance desse objetivo, esta pesquisa teórica apresentou: elementos do referencial teórico que dialogou com os conceitos relevantes ao tema; foram levantados, anos, países, e autores com maior número de publicação; conceitos, tendências de pesquisa, elementos e a agenda de pesquisas em governança inteligente.

Ao fazer o levantamento teórico sobre a temática da governança em cidades inteligentes, foi verificado que a governança na perspectiva das cidades inteligentes privilegia o uso da tecnologia da informação aliada à participação da sociedade como forma de maior assertividade nos serviços prestados à população, saindo assim do mero cumprimento de normas e trazendo a sociedade para o centro do diálogo. 
Destaca-se também que há diferenças nos termos governo inteligente e governança inteligente, sendo conceitos distintos da produção do produção do conhecimento em cidades inteligentes. Também fizeram parte dessa abordagem teórica os elementos do governo eletrônico e governo aberto como ferramentas de integração da sociedade com o meio público, sendo o governo aberto o responsável por disponibilizar dados à população e o governo eletrônico o meio de acesso da sociedade à informação.

Concluiu-se também que o conceito de governança inteligente se dá pela associação entre uso da tecnologia e envolvimento dos atores locais, em especial o cidadão, para definição mais acertada das políticas públicas, coprodução de serviços e práticas de governo, gerando uma maior confiança na administração pública.

Também foram constatados alguns elementos que colaboram para o desenvolvimento da governança inteligente ou são gerados a partir do seu desenvolvimento, sendo alguns deles: dados, transparência, participação, contexto, cidadão, colaboração, desenvolvimento, tecnologia da informação e comunicação, e meio ambiente. Destaca-se esse ponto, pois é um elemento que merece um estudo específico para melhor detalhamento desses elementos que formam a governança inteligente.

A contribuição da pesquisa no âmbito acadêmico se dá por sua capacidade de apresentar direcionamentos sobre o tema da governança; temática, de forma isolada, ainda pouco explorada, servindo assim de base para o aprofundamento dos estudos relacionados a cidades inteligentes e em especial ao aspecto da governança. Assim como busca propor aspectos relevantes a serem estudados nessa temática. Gerencialmente, a contribuição está associada ao levantamento de características existentes na governança da cidade inteligente, que pode servir de base para o desenvolvimento de projetos de governança nas cidades.

Para estudos futuros, com base na agenda de pesquisas, indicam-se: estudos que abordem aproximação entre os atores sociais; mecanismos de participação em plataformas eletrônicas; definição de estratégias e normas; avaliação da real inclusão do cidadão na cidade inteligente; capacitação do cidadão na participação da governança da cidade; desenvolvimento de modelo de referência com capacidade de inferência estatística; avaliação das políticas adotadas pelas cidades para a operacionalização de ações de transparência, colaboração, participação e parceria, comunicação e responsabilidade; igualdade de gênero em cidades inteligentes. 


\section{Referências bibliográficas}

AlBINO, V.; BERARDI, U.; DANGELICO, R. M. Smart cities: definitions, dimensions, performance, and initiatives. Journal of Urban Technology, v. 22, n.1, p. 3-21, 2015.

Al-Rababah, B. A.; AbU-Shanab, E. A. Egovernment and gender digital divide: the case of Jordan. International Journal of Electronic Business Management, v. 8, n. 1, p. 1-8, 2010.

ANTHOPOULOS, L. Smart utopia VS smart reality: learning by experience from 10 smart city cases. Cities, v. 63, p. 128-148, 2017.

ARTMAnN, M. et al. How smart growth and green infrastructure can mutually support each other conceptual framework for compact and green cities. Ecological Indicators, v. 96, p. 10-22, 2019.

Ballas, D. What makes a 'happy city'? Cities, v. 32, p. S39-S50, 2013.

BASU, S. E-Government and developing countries: an overview. International Review of Law Computers \& Technology, v. 18, n. 1, p. 109132, 2004.

BEN YAHIA, N.; ElJAOUED, W.; BELlAMINE BEN SAOUd, N.; COLOMO-PALACIOS, R. Towards sustainable collaborative networks for smart cities co-governance. International Journal of Information Management, p. 102037, 2019.

Berrone, P.; RICART, J. E. IESE Cities in Motion Index 2020. Barcelona: IESE Business School (University of Navarra), 2020. Disponível em: https://media.iese.edu/research/pdfs/ST-0542E.pdf. Acesso em: 06 ago. 2020.

BERTOT, J. C. et al. Big data, open government and e-government: issues, policies and recommendations. Information Polity, v. 19, p. 516, 2014.

BIBRI, S. E.; KROGSTIE, J. Smart sustainable cities of the future: an extensive interdisciplinary literature review. Sustain. Cities. Soc., v. 31, p. 183-212, 2017.
BINGHAM, L. B.; NABATCHI, T.; O'LEARY. The new governance: practices and processes for stakeholder and citizen participation in the work of government. Public Administration Review, v. 65, n. 5, p. 547-558, 2005.

BLANCO, I. Between democratic network governance and neoliberalism: a regimetheoretical analysis of collaboration in Barcelona. Cities, v. 44, p. 123-130, 2015.

BOLÍVAR, M. P. R. Governance in smart cities: a comparison of practitioners' perceptions and prior research. Smart cities and smart spaces: concepts, methodologies, tools, and applications. IGI Global, 2019.

BOLÍVAR, M. P. R. Governance in smart cities: a comparison of practitioners' perceptions and prior Research. International Journal of E-Planning Research (IJEPR), v. 7, n. 2, p. 1-19, 2018.

CAPDEVIlA, I.; ZARLENGA, M.I. Smart city or smart citizens? The Barcelona case. Journal of Strategy and Management, v. 8, n.3, p. 266-282, 2015.

CAPuto, F.; WAlletzKY, L.; ŠTEPÁNEK, P. Towards a systems thinking based view for the governance of a smart city's ecosystem: a bridge to link Smart Technologies and Big Data. Kybernetes, v. 48, n. 1, p. 108-123, 2018.

ChOURABI, H.; NAM, T.; WALKer, S.; GILGARCIA, J. R.; MElloUli, S.; NAHON, K.; PARDO, T. A.; SCHOLL, H. J. Understanding smart cities: an integrative framework. In: HAWAII INTERNATIONAL CONFERENCE ON SYSTEM SCIENCES, 45, 2012, Hawaii. Anais... Hawaii: ICSS, 2012. Disponível em: https://dl.acm.org/citation.cfm?id=2117151. Acesso em: 15 set. 2018.

CHUN et al. Government 2.0: making connections between citizens, data and government. Information Polity, v. 15, p. 1-9, 2010.

COGLIANESE, C. The transparency president? the Obama administration and open government. Governance: An International Journal of Policy, 
Administration, and Institutions, v. 22, n. 4, p. 529-544, 2009.

De Guimarães, J. C. F.; Dorion, E. C. H.; SEVERO, E. A. Antecedents, mediators and consequences of sustainable operations. Benchmarking: An International Journal, 2019.

DE GUIMARÃES et al. Governance and quality of life in smart cities: towards sustainable development goals. Journal of Cleaner Production, v. 253, 2020.

Del Esposte, A. D. M.; SANTANA, E. F.; KANASHIRO, L.; COSTA, F. M.; BRAGHETTO, K. R.; LAGO, N.; KON, F. Design and evaluation of a scalable smart city software platform with largescale simulations. Future Generation Computer Systems, v. 93, p. 427-441, 2019.

ECK, N. J. V.; WALYMAN, L. CitNetExplorer: a new software tool for analyzing and visualizing citation networks. Journal of Informetrics, v. 8, n. 4, p. 1-37, 2010.

EGER, J. M. Smart growth, smart cities, and the crisis at the pump a worldwide phenomenon. Journal of E-Government Policy and Regulation, v. 32, p. 47-53, 2009.

EUROPEAN PARLIAMENT. Mapping smart cities in the EU. Brussels, Belgium: European Parliament, Directorate General for internal policies, 2014. Disponível em: europarl.europa.eu/RegData/etudes/etudes/join/20 14/507480/IPOLITRE_ET(2014)507480_EN.pdf. Acesso em: 19 jun. 2019.

FeliX Júnior, L. A.; COSTA, W. P. L. B.; Guimarães, L. G. A; Pereira, G. R. B.; ELAOUAR, W. A. Social participation in the definition of budgetary instruments. Transforming government: people, process and policy, 2020a.

Felix Júnior, L. A.; Guimarães, L. G. A.; Dias Segundo, E. M.; BAtista Da Costa, W. P. L.; ABBAS EL-AOUAR, W. Open government and egovernment: concepts, gaps, interfaces, and trends. In: FARAZMAND, A. (Org.). Global Encyclopedia of Public Administration, Public Policy, and Governance. $1^{\mathrm{a}}$. ed. Cham: Springer International Publishing, 2020b.
GIFFINGER, R.; FERTNER, C.; KRAMAR, H.; KALASEK, R.; PICHLER-MILANOVIC, N.; MEIJERS, E. Smart cities Ranking of European mediumsized cities. 2007. Disponível em: http://www.smartcities.eu/download/smart_cities_final_report.pdf. Acesso em: 15 set. 2018.

GIFFINGER, R.; HAINDLMAIER, G.; KRAMAR, H. The role of rankings in growing city competition. Urban Research \& Pratice, v. 3, n. 3, p. 299-312, 2010.

GIL, O.; CORTÉS-CEDIEL, M.E.; CANTADOR, I. Citizen participation and the rise of digital media platforms in smart governance and smart cities. International Journal of E-Planning Research (IJEPR), v. 8, n. 1, p. 19-34, 2019.

GIL-GARCIA, J. R. Towards a smart State? Interagency collaboration, information integration, and beyond. Information and Polty, v. 17, p. 269-280, 2012.

GIL-GARCIA, J. R.; Helbig, N.; OJO, A. Being smart: emerging technologies and innovation in the public sector. Government Information Quarterly, v. 31, p. I2 - I8, 2014.

GIL-GARCIA, J. R.; PARDO, T. A. E-government success factors: mapping practical tools to theoretical foundations. Government Information Quarterly, v. 22, p. 187-216, 2005.

GlASMEIER, A. K.; NeBIOLO, M. Thinking about smart cities: the travels of a policy idea that promises a great deal, but so far has delivered modest results. Sustainability, v. 8, n. 11, p. 1-11, 2016.

Hammad, A. W.; AKBARnezHad, A.; HADDAD, A.; VAZQUEZ, E. G. Sustainable zoning, land-use allocation and facility location optimisation in smart cities. Energies, v.12, n.7, p. 1-23, 2019.

JiAnG, H.; GeERTMan, S.; WitTe, P. Smart urban governance: an urgent symbiosis? Information Polity, v. 24, n. 3, p. 245-269, 2019.

KumMitha, R. K. R.; CRUTZEN, N. How do we understand smart cities? An evolutionary perspective. Cities, v. 67, 43-52, 2017. 
LAM, W. Barriers to e-government integration. The Journal of Enterprise Information Management, v. 18, n. 5, p. 511-530, 2005.

LETAIFA, S. B. How to strategize smart cities: revealing the SMART model. Journal of Business Research, v.68, n.7, 1414-1419, 2015.

LIN, Y. A comparison of selected Western and Chinese smart governance: the application of ICT in governmental management, participation and collaboration. Telecommunications Polity, v. 42, n. 10, p. 800-809, 2018.

LIN, Y.; ZHANG, X.; GEERTMAN, S. Toward smart governance and social sustainability for Chinese migrant communities. Journal of Clean Production, v. 107, p. 389-399, 2015.

LOPES, I. M.; OLIVEIRA, P. Can a small city be considered a smart city? Procedia Computer Science, v. 121, p. 617-624, 2017.

LYNN, L. E.; HeINRICH, C. J.; HILL, C. J. Studying governance and public management: challenges and prospects. Journal of Public Administration Research and Theory, v. 10, n. 2, p. 233-262, 2000.

Martínez, A. C. I. Com obrir les caixes negres de les Administracions públiques? Transparència i rendició de comptes en l'ús dels algoritmes (CAEN). Revista catalana de dret públic, p. 13-28, 2019.

MEIJER, A. J. Smart City Governance: a Local Emergent Perspective. In: GIL-GARCIA, J. R.; PARDO, T. A.; NAM, T. Smarter as the new urban agenda. Switzerland: Springer International Publishing, 2016.

Bolívar, M. P. R.; MeIJer, A. Governing the smart city: a review of the literature on smart urban governance. International Review of Administrative Sciences, v. 82, n. 2, p. 392-408, 2016.

MeIJER, A. J.; GIL-GARCIA, J. R.; Bolívar, M. P. R. Smart City Research: Contextual Conditions, Governance Models, and Public Value Assessment. Social Science Computer Review, v. 34, n. 6, p. 647-656, 2016.
MeIJER, A.; THAENS, M. Quantified street: smart governance of urban safety. Information Polity, v.23, p.29-41, 2018.

MongeOn, P.; PAul-Hus, A. The journal coverage of Web of Science and Scopus: a comparative analysis. Scientometrics, v. 1, n. 106, p. 213-228, 2016.

MoolJ, J. Smart governance? Politics in the policy process in Andhra Pradesh, India. ODI Working Papers, 228, 2003. Disponível em: http://www.odi.org.uk/resources/download/1793.p df. Acesso em: 18 set. 2018.

NAM, T.; PARDO, T. A. Conceptualizing smart city with dimensions of technology, people, and institutions. In.: ANNUAL INTERNATIONAL DIGITAL GOVERNMENT RESEARCH CONFERENCE: DIGITAL GOVERNMENT INNOVATION IN Challenging Times, 12, 2011, New York. Anais Eletrônicos ... New York: AIDGRC, 2011. Disponível em: https://intaaivn.org/images/cc/Urbanism/background\%20doc uments/dgo_2011_smartcity.pdf. Acesso em: 30 ago. 2020.

NAM, T.; PARDO. T. A. The changing face of a city government: a case study of Philly 311. Government Information Quarterly, v. 31, p. s1s9, 2014.

NEIS, P.; ZIELSTRA, D.; ZIPF, A. The street network evolution of crowdsourced maps: openStreetMap in Germany 2007-2011. Future Internet, v. 4, n. 1, p. 1-21, 2012.

NeSTI, G. Defining and assessing the transformational nature of smart city governance: insights from four European cases. International Review of Administrative Sciences, v. 86, n.1, p. 118,2018

NESTI, G. Mainstreaming gender equality in smart cities: theoretical, methodological and empirical challenges. Information Polity, v. 24, n. 3, p. 289304, 2019.

Nesti, G.; GraZIAnO, P. R. The democratic anchorage of governance networks in smart cities: an empirical assessment. Public Management Review, v. 22, n. 5, p. 648-667, 2020.

ODENDAAL, N. Information and communication technology and local governance: understanding 
the difference between cities in developed and emerging economies. Computers,

Environmentand Urban Systems, v. 27, p. 585607, 2003.

OrsZag, P. R. Open Government Directive: memorandum for the heads of executive departments and agencies. Executive Office of the President, Office of Management and Budget, Ed. Washington, DC: The White House, p. 1-11, 2009. Disponível em: https://www.hsdl.org/?abstract\&did=31268. Acesso em: 22 dez. 2018.

PAlOMO-NAVARRo, A.; NAVÍO-MARCO, J. Smart city networks' governance: The Spanish smart city network case study. Telecommunications Policy, v. 42, n. 10, p. 872-880, 2018.

PEREIRA, G.V.; CUNHA, M. A.; LAMPOLTSHAMMER, T. J.; PARYCEK, P.; TESTA, M. G. Increasing collaboration and participation in smart city governance: a cross-case analysis of smart city initiatives. Information Technology for Development, v. 23, n. 3, p. 526-553, 2017.

Pereira, G.V.; Eibl, G.; StYlianOU, C.; MartíneZ, G.; NeOPhYTOU, H.; PARYCEK, P. The role of smart technologies to support citizen engagement and decision making: the SmartGov case. International Journal of Electronic Government Research, v. 14, n. 4, p. 1-17, 2018 a.

Pereira, G.V.; PARYCEK, P.; FAlco, E.; KLEINHANS, R. Smart governance in the context of smart cities: a literature review. Information Polity, v. 23, p. 143-162, 2018 b.

RAKODI, C. Urban governance and povertyaddressing needs, asserting claims: an editorial introduction. International Planning Studies, v. 6, n. 4, p. 343-356, 2001.

RAZAGHI, M.; FINGER, M. Smart governance for smart cities. Proceedings of the IEEE, v. 106, n. 4, p. 680-689, 2018.

RomanelLI, M. Analysing the role of information technology towards sustainable cities living. Kybernetes, v. 49, n.7, 2020.

RANCHOD, R. The data-technology nexus in South African secondary cities: the challenges to smart governance. Urban Studies, p. 1-18, 2020.
RotTA, M.J.R.; Sell, D.; Dos SANTOS PACHECO, R.C.; YIGITCANLAR, T. Digital commons and citizen coproduction in smart cities: assessment of Brazilian municipal e-government platforms. Energies, v. 12, n. 14, p. 2813, 2019.

RUHLANDT, R. W. S. The governance of smart cities: a systematic literature review. Cities, v. 81, p. 1-23, 2018.

SCHOLL, H. J.; SCHOLL, M. C. Smart governance: a roadmap for research and practice. In: ICONFERENCE 2014 PROCEEDINGS, 2014, Berlim. Anais... Berlim: IConference, 2014. p. 163-176.

SHIM, D. C.; EOM, T. H. E-government and anticorruption: empirical analysis of international data. International Journal of Public Administration, v. 31, n. 3, p. 298-316, 2008.

SIFAH, E. B.; XIA, H.; CobBlaH, C. N.; XIA, Q.; GAO, J.; DU, X. BEMPAS: a decentralized employee performance assessment system based on blockchain for smart city governance. IEEE Access, 2020.

Silva, A. O.; Fernandes, R. A. S. Smart governance based on multipurpose territorial cadastre and geographic information system: an analysis of geoinformation, transparency and collaborative participation for Brazilian capitals. Land Use Policy, v. 97, p. 104752, 2020.

TAHIR, Z.; MALEK, J. A. Main criteria in the development of smart cities determined using analytical method. Planning Malaysia, v.14, n.5, 2016.

THUZAR, M. Urbanization in SouthEast Asia: developing smart cities for the future? Regional Outlook, p.96-100, 2011.

TOMOR, Z.; MEIJER, A.; Michels, A.; GeERTMAN, S. Smart governance for sustainable cities: findings from a systematic literature review. Journal of Urban Technology, v. 26, n. 4, p. 3-27, 2019.

WALRAVEns, N.; BALlON, P. Platform business models for smart cities: from control and value to governance and public value. IEEE Communications Magazine, p. 72-79, 2013. 
WeBSTER, C. W. R.; LelEuX, C. Smart governance: opportunities for technologicallymediated citizen co-production. Information Policy, v. 23, p. 95-110, 2018.
WILLKE, H. Smart governance: governing the global knowledge society. Campus Verlag, 2007.

YoLLES, M. Governance through political bureaucracy: an agency approach. Kybernetes, v. 48 , n. 1, p. 7-34, 2019.

\section{Luiz Antônio Felix Júnior}

https://orcid.org/0000-0001-7427-6673

Professor do Instituo Federal de Alagoas (IFAL - Campus Benedito Bentes). Doutorando em Administração no Programa de Pós-Graduação em Administração da Universidade Potiguar (PPGA/UnP). Mestre em Ciências Contábeis pela Universidade Federal de Pernambuco. Especialista em Docência no Ensino Superior pelo Centro Universitário Senac e Bacharel em Ciências Contábeis pela Universidade Federal da Paraíba. E-mail: luiz.felix@ifal.edu.br

\section{Luciana Gondim de Almeida Guimarães}

https://orcid.org/0000-0002-6765-6843

Pós-Doutora pelo Centre Interuniversitaire de Recherche sur les Réseaux Dentreprise, la Logistique et le Transport (CIRRELT) na Université Laval em Quebec - Canadá. Doutora em Administração pela Universidade Federal de Pernambuco. Mestra em Logística e Pesquisa Operacional pela Universidade Federal do Ceará. Bacharel em Administração de Empresas pela Universidade Estadual do Ceará. Professora do Programa de Pós-Graduação em Administração na Universidade Potiguar (PPGA/UNP). Assistente de pesquisa na Université Laval.

E-mail: luciana.almeida@unp.br

\section{Wênyka Preston Leite Batista da Costa}

iD https://orcid.org/0000-0002-6494-1454

Doutora e Mestra em Administração pela Universidade Potiguar. Especialista em Auditoria Contábil e Bacharel em Ciências Contábeis pela Universidade do Estado do Rio Grande do Norte. Professora do Departamento de Ciências Contábeis da Universidade do Estado do Rio Grande do Norte.

E-mail: wenykapreston@ hotmail.com

\section{Vera Lúcia Cruz}

https://orcid.org/0000-0002-6258-3358

Doutora em Administração pela Universidade Potiguar. Mestra em Ciências Contábeis pela Universidade Federal de Pernambuco. Bacharel em Ciências Contábeis pela Universidade Católica de Pernambuco. Professora dos cursos de Ciências Contábeis e Ciências Atuariais da Universidade Federal da Paraíba (Campus I).

E-mail: vera.cruz@ccsa.ufpb.br

\section{Walid Abbas El-Aouar}

http://orcid.org/0000-0003-4033-7655

Doutor, mestre e Bacharel em Administração pela Universidade Federal do Rio Grande do Norte. Pesquisador e Professor titular do Programa de Doutorado e Mestrado em Administração da Universidade Potiguar (PPGA/UnP).

E-mail: walidabbas@unp.br 